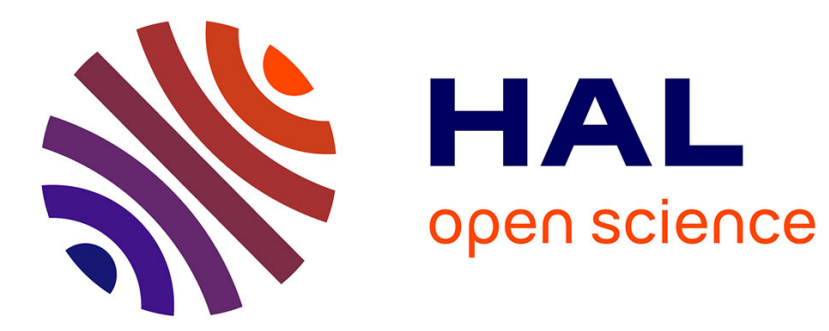

\title{
Spatial augmented reality to enhance physical artistic creation.
}

Jérémy Laviole, Martin Hachet

\section{To cite this version:}

Jérémy Laviole, Martin Hachet. Spatial augmented reality to enhance physical artistic creation.. Adjunct proceedings of the 25th annual ACM symposium on User interface software and technology, Oct 2012, Cambridge, MA, United States. pp.43-46, 10.1145/2380296.2380316 . hal-00724116

\section{HAL Id: hal-00724116 https://hal.inria.fr/hal-00724116}

Submitted on 31 Aug 2012

HAL is a multi-disciplinary open access archive for the deposit and dissemination of scientific research documents, whether they are published or not. The documents may come from teaching and research institutions in France or abroad, or from public or private research centers.
L'archive ouverte pluridisciplinaire HAL, est destinée au dépôt et à la diffusion de documents scientifiques de niveau recherche, publiés ou non, émanant des établissements d'enseignement et de recherche français ou étrangers, des laboratoires publics ou privés. 


\section{Spatial augmented reality to enhance physical artistic creation.}

\author{
Jeremy Laviole \\ Univ. Bordeaux, LaBRI, UMR 5800, F-33400 \\ Talence, France. \\ CNRS, LaBRI, UMR 5800, F-33400 Talence, \\ France. \\ Inria, F-33400 Talence, France. \\ laviole@labri.fr
}

\author{
Martin Hachet \\ Inria, F-33400 Talence, France. \\ LaBRI, UMR 5800, F-33400 Talence, France. \\ martin.hachet@inria.fr
}

\begin{abstract}
Spatial augmented reality (SAR) promises the integration of digital information in the real (physical) world through projection. In this doctoral symposium paper, I propose different tools to improve speed or ease the drawing by projecting photos, virtual construction lines and interactive 3D scenes. After describing the tools, I explain some future challenges to explore such as the creation of tools which helps to create drawings that are "difficult" to achieve for a human being, but easy to do by a computer. Furthermore, I propose some insights for the creation of digital games and programs which can take full advantages of physical drawings.
\end{abstract}

ACM Classification: H5.1 [Information interfaces and presentation]: Multimedia Information Systems. - Artificial, augmented, and virtual realities

\section{General terms: Design, Human Factors}

Keywords: Spatial augmented reality, user interfaces, arts, interactive projection

\section{INTRODUCTION}

In the past few years, augmented reality has reached the general public. This is due to the availability of webcams in laptops and mobile phones and software such as ARToolKit [11]. The augmentations are overlayed on reality and visualized though a screen. Although it is convenient to have a view of the digital elements though a screen, it will create important limitations on the field of view. In order to overcome these limitations, the digital information can be projected into reality; this is called spatial augmented reality (SAR) [9].

In SAR, the visualizations and interactions space are the same; leading to more natural user experiences. Conversely, SAR applications are bounded to real-life, thus it is harder

Permission to make digital or hard copies of all or part of this work for personal or classroom use is granted without fee provided that copies are not made or distributed for profit or commercial advantage and that copies bear this notice and the full citation on the first page. To copy otherwise, to republish, to post on servers or to redistribute to lists, requires prior specific permission and/or a fee.

UIST'12, October 7-10, 2012, Cambridge, MA, USA.

Copyright 2012 ACM 978-1-xxxx-xxxx-x...\$10.00. to represent data behind real objects because the projection support will importantly influence the visualization. Recent work in SAR explores the projection support as the main interaction element. The augmented reality part will add new information, some ideas for applications are described in [8]. In [10], a similar idea is explored: the projection guides the user's movement by projecting on the user's hand. In [12] and [4] the freedom of movement of SAR is used to create games which adapts itself to the projection support. Another approach in [3], is to use SAR directly on the user's arm or a notepad to control a mobile phone or take notes. Flagg et. al. [1] created a SAR application to ease the painting process, they propose tools to help the user to mix fresh paint and to apply the different layers in the right order.

This kind of SAR in context is very promising; it is a first step for a more natural merge of the digital world and the real world. Applications that fits on the physical world make reality richer and more interactive. In this paper, I state the objectives which led to my past and current works on SAR for drawing. Then, I will conclude with a discussion of the future possibilities such as the integration of physical drawing in digital applications.

\section{Motivations for SAR for physical drawing.}

There are many advantages to create digital drawings instead of physical ones. The most important one, is the possibility to go back and try again; which is obviously impossible in the physical world. Some of the many possibilities includes: the flexibility of digital layers, the copy/paste operations, filling regions with colors and textures and zooming operations.

Conversely, physical creation allows a direct contact between the artist and the creation. The result will be unique and will contain traces of all the errors corrected. The variety of tools comes from a legacy of thousands of years of artistic creations. Each pen or paint has its own smell and behaviour on the paper and tactile feeling. The link between the artist, his or her tools and the resulting creation has history: from the acquisition of tools, to the whole creation process to achieve the desired result, or not. This link may be different from the one with digital creation, the choice of a digital brush or effect does not have any cost; the artist does not even need to leave the computer. 


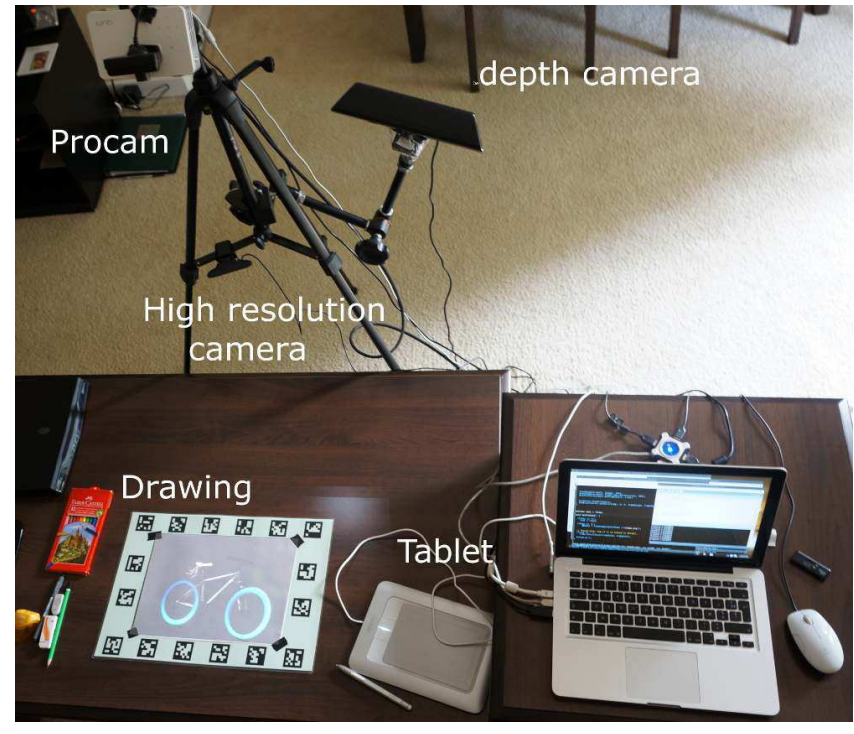

Figure 1: View of the system in a home configuration. The whole sensing and projecting system is mounted on a tripod, making it easily transportable.

In order to use the possibilities of real-time rendering, the artist will need to visualize and modify a 3D scene. In the next section, I present the system I created which enables projection on interactive sheets of paper, allowing the projection of photos to interactive 3D scenes.

\section{Spatial augmented reality and interactivity The system}

For the creation of the system, we wanted to have as few constraints as possible: no constraint on the creation tools nor on the drawing support. More importantly, we wanted to keep a large freedom of movement. Consequently, the system does not add any constraint to the traditional drawing configuration, and seamlessly integrate the digital elements within it.

The hardware system is composed of a small projector-camera (procam) set, and a depth camera, as seen in Figure 1. We chose overhead projection to enable any drawing support, and we use the depth camera to make the system interactive. The user interface is composed of tracked sheets of paper: one or more is dedicated to the creation space. The paper or canvas is surrounded by markers to achieve a high precision detection of its position. The whole drawing area is made tactile by the depth camera, even allowing 3D pointing interactions over it. Another piece of paper is used for the user interface, generally containing virtual buttons.

The goal of the system is to achieve a high speed tracking and more importantly high-fidelity projection. As the tracking speed may make the system less appealing or slow the user, a bad calibration will make it unusable. The capture and projection process requires a precise calibration to achieve the desired results. The hardware used is widely available for a moderate cost, the projector used is a DLP LED projector, the camera and depth camera are video game console accessories. For more informations, please refer to [5].

\section{D projection and manipulation}

The firsts experiments involved the projection of photos inside the tracked piece of paper. The task was to create a drawing from the projected image, while the projection acts as tracing paper. Some results are presented in Figure 2. From these experiments, we had some user feedback; the tracking does not have to be fast during the drawing phase: when the user moves the drawing support, he or she can wait a second or two before drawing again. Another point is that any spatial shift between the projection and the drawing will make the drawing much harder, and less comfortable. We also included tools to change the intensity of the projection, which was necessary to add any details to the drawings. Each of our testers were adults, and most of them do not draw at all. Still, once they started the drawing, they took between 35 to 45 minutes uninterrupted to draw. Most of them did not take so much time drawing since their childhood and were happy with the result.

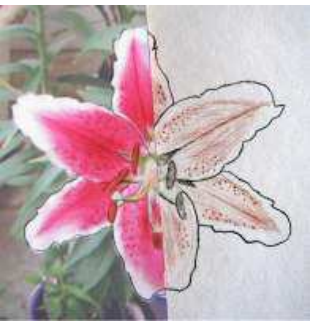

(a) A lily flower.

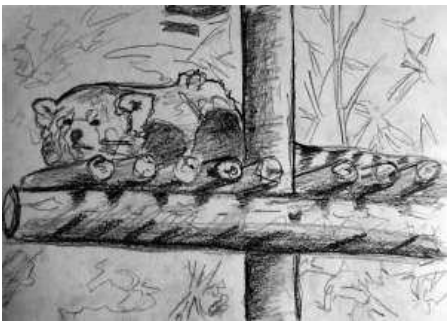

(b) A red panda.
Figure 2: The projection of photos on the tracked paper sheet is an easy way to create drawings, more comfortable to use than a tracer projector.

The second application that we developed allows the projection of a 3D scene. A 3D object is projected onto the sheet of paper and behaves as if it was directly on the piece of paper. Consequently, if you see the front and want to see the back of the object, you just need to turn the piece of paper on the table. We also included rotate, scale and translate operations using the touch interface, allowing an easier modification of the scene. The point of view of the scene is set to the user's head position, but generally we held it fixed to make the system more robust and to keep it cheap. The 3D pointing was used to set a virtual light inside the virtual scene. The tangible interface and light placement enhance the perception of the 3D objects. We enhanced it by adding stereoscopic rendering. Using this system, we created an application and a drawing scenario for a general public exhibition in Paris.

\section{General public exhibition}

The exhibition lasted more than 3 month, and we were demonstrating and experimenting for more than 12 days. The aim of the demonstration was to explain our research to the general public and to let the visitors experiment. We designed a drawing application using the projection of the $3 \mathrm{D}$ scene. We could explain the current challenges of visualization and manipulation of virtual objects. After describing our system and solutions, we could make a quick drawing and let a visitor do another one while answering the questions.

In order to speed up the drawing phase, we used a simple 


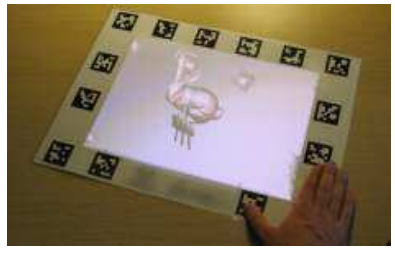

(a) Before rotation

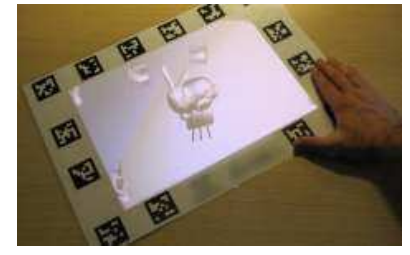

(b) After rotation
Figure 3: The paper sheet is used a a tangible interface. While its moving, the rendering adapts the view to the new location.

toon shading for the rendering of the scene and a 3D model which was simple to draw, as illustrated in Figure 4. The whole description of the system and elements of the presentation were done only using the touch and tangible interface; the mouse, keyboard and screen of the computer were hidden from the visitors.

The reception of the general public was positive, and seemed "magical" for some visitors. When the sheets of paper are on the table, the system is interactive, but without any piece of paper it is just a table with a few pencil and an eraser. We tested our drawing system on about 200 visitors, and nearly every one of them was impressed by the quality of their own drawing.
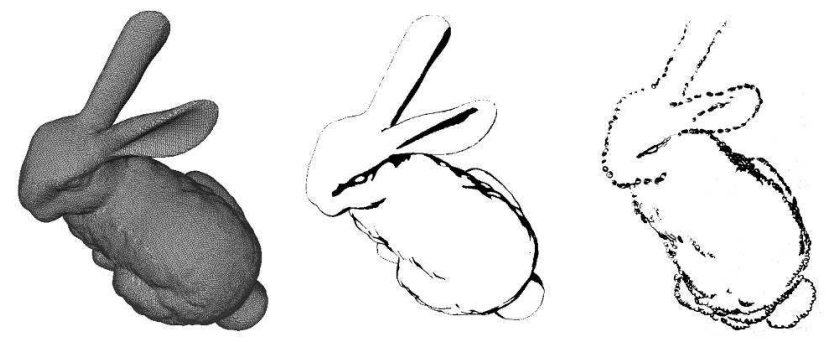

Figure 4: Illustration of the drawing process. A 3D model is rendered using toon shading and projected. On the right is the resulting drawing.

\section{Pushing the limits of drawing}

The first difficult drawing I explored with this is stereoscopic drawing. Recently, stereoscopic screens are widely available, and "3D" movies are getting more and more common. The creation of stereoscopic drawing is hard and repetitive: two nearly identical drawings have to be made. Moreover, the visualization of these drawings require training for freeview techniques (without any tool) or more generally a stereoscope. In [6], we proposed a tool to create stereoscopic drawings from a pair of generated images. The images are created using the hardware and software described above.

Just like any typical drawing, stereoscopic drawings require editions and adjustments. However, stereoscopic drawing is unique because it has to be done twice, and the differences between the two drawings will influence the depth perception of the result. We also included the possibility of taking an image of each drawing in order to have stereoscopic preview of the result (anaglyph).
These experiments have raised many questions and observations. The first observation is on the quality of the drawing: the depth perception will be more influenced by the quality of the shading than by the left/right disparity. With this kind of tools, we could reconstruct a stereoscopic drawing from two (or more) partial drawing. However the final result would be dependant of the digital world.

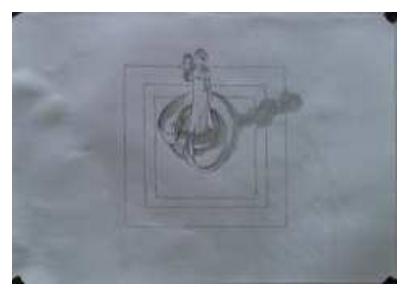

(a) Left view

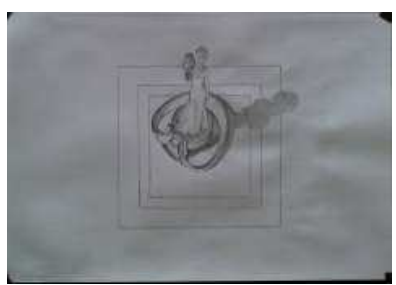

(b) Right view
Figure 5: Stereographic pair of drawings.

\section{Perspectives of SAR for drawing Interaction techniques}

The inputs and interaction techniques described above allow direct and natural interactions. But, it is not precise enough for selection and manipulation of digital information. In order to complement these we added a highly precise tablet input (wacom); it allows to overlay digital drawing over the physical one. We also included the possibility of capturing the drawing. This way, the drawing itself can be considered as an input method, as in [2].

\section{New forms of creation}

From our first experiments, most of the users really liked the result of the mix between the real drawing and the projection. The real drawing generally makes the contour stronger and represent the interesting features of the image; while the projection provide complex texture and colors that are very difficult to draw. From these, we could allow the creation of hybrid drawings, partly physical and partly digital, a simple example illustrate this in Figure 6 The physical drawing may keep blank or less intense parts allowing the projection. The projected elements, unlike drawn elements can contain animations, which enables an interactive exploration of the drawing, or animated drawings. It could also be used for storytelling: as storyteller draws elements, it could start sounds, animations or videos around it, creating a richer experience.

\section{Digital games applications}

The fact that a drawing leaves a trace, takes time and can contain errors makes it a good candidates for game creations. For example, for real-time strategy games: instead of just adding buildings using the mouse, the player could draw each building. The quality of the drawing could be evaluated to set its properties. The drawing process takes times, and the fact that the quality of the drawing is implied in the game will force to user to make choices on quality or speed. The limitations will not be game limitations, but also player limitations. The difficulty levels could imply new drawing skills, such as special shading techniques, or high speed drawing; consequently adding a pedagogical side on these games.

One could also create construction games, such as Sim City. 


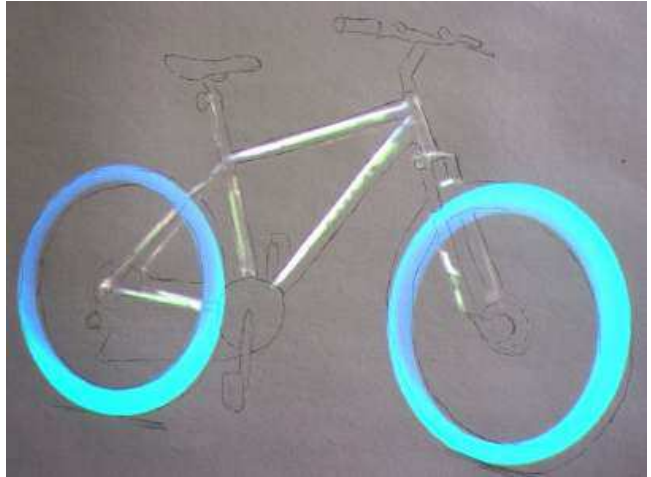

Figure 6: Photo of a hybrid combination between a physical drawing, real colors from a photo and extra colors added using an image edition software.

Instead of creating a digital city, the city map is drawn directly on the paper, and virtual citizens could come and create their own houses. As described above, the creation of special building could be man-made, and it will create another dimension of the game. The player will think twice when placing the schools and fire station, because moving them will require real time and effort.

\section{Extensions}

Most of the applications described does not rely on advanced computer graphics techniques. However, some recent works such as ShadowDraw [7] shows a desire of the computer graphics community to get closer to the physical world. We could imagine tools assisting the creation of multi-perspective drawings or complex anamorphosis. These kinds of drawings require a wide variety of skills that could be compensated by programs.

Another natural extension, would be the use of the capture and reprojection for the creation of traditional animation. It would be a compelling challenge to take advantage of the digital animation tools, and port them to be used for physical images.

We proposed some tools to draw 3D objects. An interesting, though difficult approach would be to use multiple drawings to interactively construct a 3D model. The first creations of the designers are generally on paper, and they are multiple view of the objects. It makes them a perfect candidate for interactive reconstruction of the imagined $3 \mathrm{D}$ object. This way the designer may create more drawings, and achieve a better inner representation of the object.

\section{Conclusion}

In this paper I summarized the most interesting work and thoughts of nearly two years of work. The creation of the SAR installation required the acquisition of new knowledge from computer vision and computer graphics. The possibilities with this kind of installation are just starting to be explored. The creation of each application raised many questions touching the fields of computer vision, human perception, computer graphics and challenging design choices. We proposed solutions to ease the drawing, and had the possibility to try them with the general public.

\section{REFERENCES}

1. M. Flagg and J.M. Rehg. Projector-guided painting. In Proceedings of the 19th annual ACM symposium on User interface software and technology, pages 235244. ACM, 2006.

2. N. Hagbi, O. Bergig, J. El-Sana, and M. Billinghurst. Shape recognition and pose estimation for mobile augmented reality. In Mixed and Augmented Reality, 2009. ISMAR 2009. 8th IEEE International Symposium on, pages 65-71. IEEE, 2009.

3. C. Harrison, H. Benko, and A.D. Wilson. Omnitouch: wearable multitouch interaction everywhere. In Proceedings of the 24th annual ACM symposium on User interface software and technology, pages 441450. ACM, 2011.

4. B.R. Jones, R. Sodhi, R.H. Campbell, G. Garnett, and B.P. Bailey. Build your world and play in it: Interacting with surface particles on complex objects. In Mixed and Augmented Reality (ISMAR), 2010 9th IEEE International Symposium on, pages 165-174. IEEE, 2010.

5. Jérémy Laviole and Martin Hachet. PapARt: interactive 3D graphics and multi-touch augmented paper for artistic creation. IEEE Symposium on $3 D$ User Interfaces 2012, March 2012.

6. Jérémy Laviole, Fabien Lotte, and Martin Hachet. Digitally assisted stereo drawing. In The 3rd Dimension of CHI (3DCHI) - Workshop at CHI 2012, Austin, USA, May 2012.

7. Y.J. Lee, C.L. Zitnick, and M.F. Cohen. Shadowdraw: Real-time user guidance for freehand drawing.

8. P. Mistry and P. Maes. Sixthsense: a wearable gestural interface. In ACM SIGGRAPH ASIA 2009 Sketches, pages 1-1. ACM, 2009.

9. R. Raskar, G. Welch, and W.C. Chen. Table-top spatially-augmented reality: Bringing physical models to life with projected imagery. In iwar, page 64. Published by the IEEE Computer Society, 1999.

10. R. Sodhi, H. Benko, and A. Wilson. Lightguide: projected visualizations for hand movement guidance. In Proceedings of the 2012 ACM annual conference on Human Factors in Computing Systems, pages 179-188. ACM, 2012.

11. D. Wagner and D. Schmalstieg. Artoolkitplus for pose tracking on mobile devices. In Computer Vision Winter Workshop, pages 6-8, 2007.

12. A.D. Wilson. Depth-sensing video cameras for $3 \mathrm{~d}$ tangible tabletop interaction. In Horizontal Interactive Human-Computer Systems, 2007. TABLETOP'07. Second Annual IEEE International Workshop on, pages 201-204. IEEE, 2007. 